\title{
Technical-Vocational Students' Emotional Functioning Within the Bidimensional Mental Health Model
}

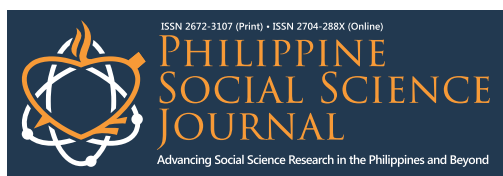

Myreen P. Cleofe ${ }^{1}$, Carmelo M. Callueng ${ }^{2}$, and Lucila O. Bance ${ }^{3}$

1, 3University of Santo Tomas- Manila, Philippines

${ }^{2}$ Rowan University, New Jersey, United States of America

\section{Article history:}

Submitted: 6 September 2021

Revised: 20 November 2021

Accepted: 21 December 2021

\section{Keywords:}

Positive psychology

Emotional functioning

Academic performance

Bidimensional model

Mental health

Philippines
ABSTRACT. There has been an increasing interest in understanding emotionality within the bidimensional mental health model (BMHM). Considered as a comprehensive framework, BMHM underscores psychological well-being and distress as related but distinct constructs contributing to an individual's overall emotionality. Following its global empirical appeal, this study was an attempt to apply the BMHM to examine the emotional functioning of 213 adolescents from a technical-vocational institution in the Philippines. Employing a cross-sectional research design, data were collected through multiple self-report measures and subsequently analyzed using descriptive and inferential statistics. Salient findings indicated that the majority of the participants were assessed with a healthy emotionality, while a small but comparable proportion reported unhealthy, diminished, and mixed emotionality. Variations in emotional functioning by gender and educational levels were significant. Additionally, participants' quality of life and academic functioning were influenced by their emotional functioning. Implications for addressing the emotional needs of students and future research were discussed.

\subsection{Introduction}

The World Health Organization (WHO, 2020) reported that almost one billion individuals live with a mental health disorder, with approximately three million people die every year due to intoxicating drinks, and one person dies of suicide every 40 seconds. The prevalence of mental health issues like anxiety, depression, and suicide in the educational setting has intensified in recent years (Auerbach et al., 2016). Rose and colleagues (2017) considered mental health as a fundamental developmental factor influencing school engagement and students' overall well-being. More specifically, psychological distress and other psychopathology symptoms can cause academic and behavior problems, including school discipline and relationship problems (Suldo \& Shaffer, 2008).

Mental illness is the third most common disability among Filipinos, with approximately six million reporting depression and anxiety; thus, the Philippines ranked as the third-highest number of mental health problems in the Western Pacific Region (WHO, 2017). A recent study conducted by the WHO reported that 3.6 million Filipinos suffer from at least one kind of mental, neurological, or substance use disorder. Moreover, suicide rates were at 3.2 per 100,000 population, with higher rates among males than females (Department of Health, 2020). Among Filipino adolescents aged 13-17 years, depression, suicide, anxiety, mood, and other behavioral and cognitive disorders were identified as the most prevalent mental health problems (WHO, 2015).

Mental health has been traditionally evaluated using a unidimensional model characterized by the presence or absence of psychopathology (Renshaw, 2017). This model posits that a low level of psychological distress is inversely proportional to a high level of psychological well-being or vice versa (Renshaw \& Cohen, 2014). It is biased to internalizing and externalizing symptoms (Renshaw \& Cook, 2018). Intervention is provided to repair damaged habits or childhood experiences (Seligman \& Csikszentmihalyi, 2000). However, opportunities for early preventive management are often overlooked (Dowdy et al., 2010). Proponents of positive psychology have advocated for a more comprehensive model that incorporates both negative and positive mental health indicators. Slade (2010) contended that understanding the dynamics of human functioning necessitates an equal consideration in promoting well-being rather than treating illness alone. Screening components that emphasize well-being and strengths may benefit in the prevention or reduction of symptom severity

This article published by Philippine Social Science Journal (PSSJ) is licensed under a Creative Commons AttributionNoncommercial 4.0 International (CC BY-NC 4.0). You are free to share (copy and redistribute the material in any medium or format) and adapt (remix, transform, and build upon the material). Under the following terms, you must give appropriate credit, provide a link to the license, and indicate if changes were made. You may do so in any reasonable manner, but not in any way that suggests the licensor endorses you or your use. You may not use the material for commercial purposes. 
(LeBuffe \& Shapiro, 2004). The bidimensional model of mental health (BMMH) (Renshaw \& Arslan, 2019) has been conceptualized as a more encompassing strategy that incorporates negative and positive mental health indicators. Using this model to assess the students' emotional functioning can provide more comprehensive information as a basis for prevention and intervention supports in the school environment.

The Philippine Mental Health Act (RA 11036) mandates schools to integrate mental health programs to promote and ensure the psychosocial wellness of students (Lally et al., 2019). Within the student population, little is known about the mental health needs of students from technicalvocational institutions. Students in this non-traditional program are subjected to an intense educational curriculum that combines academic and technical training taught in the classroom and workplace. With such rigorous academic demand, students can encounter socio-emotional difficulties associated with peer pressure, relationships with classmates or teachers, and personal challenges such as disagreements with parents and financial challenges. These multiple stressors correlate with poor mental health (Subramani \& Kadhiravan, 2017).

This study attempted to extend the application of the BMHM to understand the emotional functioning of students from a technical-vocational institution in the Philippines. Specifically, it described the students' emotional functioning profiles within a BMHM, determined gender and educational level differences in students' emotional functioning, and examined the influence of emotional functioning on quality of life and academic performance. Based on previous research, it was hypothesized that the majority of the students would report a healthy emotionality, that students' emotional functioning will vary by gender and educational levels, and that emotional functioning will influence the quality of life and academic performance.

\subsection{Framework of the Study}

Adopting a broader view of mental health that incorporates the presence of well-being in addition to low levels of psychopathology provides a more comprehensive view of the individual's emotional functioning (Grych et al., 2020). BMHM (Renshaw \& Arslan, 2019), which is synonymous with the dual-factor model (DFM; Suldo \& Shaffer, 2008), views psychological well-being and distress as two separate but complementary entities that contribute to the overall mental health of individuals (Renshaw \& Cohen, 2014). In this model, emotional functioning is described as the person's capability to lead pleasant and satisfying life (i.e., psychological well-being) while simultaneously experiencing psychological distress. Psychological well-being can encompass life satisfaction (Antaramian, 2015), positive emotions (Seligman, 2018), and meaning in life (Steger et al., 2006). On the other hand, psychological distress can include negative emotional states such as anxiety and depression (Suldo \& Shaffer, 2008). Hence, BMHM seeks to alleviate symptoms of psychopathology while at the same time cultivating the person's strengths and well-being.

As illustrated in Figure 1, BMHM classifies students' overall emotional functioning into four categories: 1) average to high levels of subjective well-being combined with low levels of psychopathology; 2) low levels of subjective well-being combined with low levels of psychopathology; 3) average to high levels of subjective well-being combined with at-risk-to-clinical levels of psychopathology; and 4) low levels of subjective well-being combined with at-risk-to-high levels of psychopathology (Renshaw \& Arslan, 2019). Other proponents label these four categories differently: complete mental health, vulnerable, symptomatic but content, and troubled (Suldo et al., 2016); welladjusted, at risk, ambivalent, and distressed (Greenspoon \& Saklofske, 2001); floundering, languishing, struggling, and flourishing (Keyes, 2002); mentally healthy, asymptomatic yet discontent, symptomatic yet content, and mentally unhealthy (Renshaw \& Cohen, 2014). Though the categories have been named differently, their defining features are similar. That is, the presence or absence of distress alone is insufficient to understand mental health, but equal consideration should be given to well-being (Renshaw \& Cohen, 2014).

The viability of such categories has been established with various samples, including adolescents, college students, and adult populations (Renshaw et al., 2016). Study shows that these categories significantly discriminated individuals by gender (Antaramian, 2015). More so, positive indicators such as grit, life satisfaction, and happiness are linked with higher educational attainment and better school performance (Eklund et al., 2010; Singh \& Jha, 2008). Key findings from various studies show that distress and well-being are distinct from one another, but they are not exclusive ends in a wellness continuum (Renshaw \& Cohen, 2014). Thus, both components must be investigated 
together to provide a broader view of psychological distress, well-being, and its relationship with overall functioning.

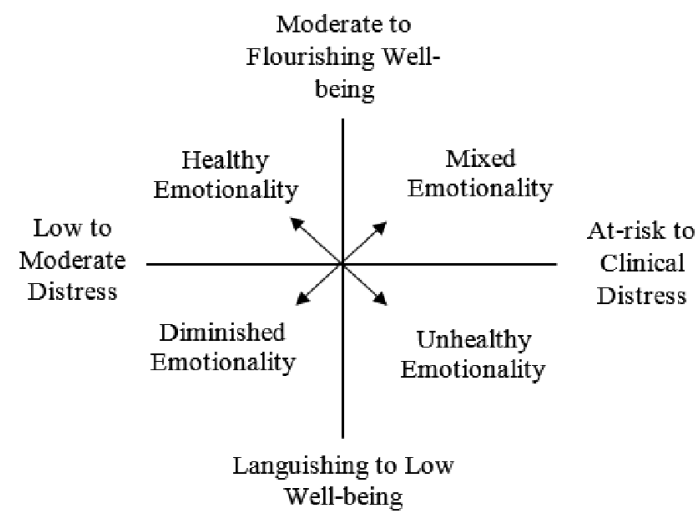

Figure 1. Bidimensional model of mental health (Renshaw \& Arslan, 2019)

\subsection{Methods}

This study utilized a cross-sectional research design to establish mental health profiles and compare groups on the study variables with data collected at a single point in time (Asenahabi, 2019). Participants were 213 students from a private technical-vocational school in the Philippines, who were primarily selected using convenience sampling. Most of the participants (77\%) were males and were living in urban areas (78\%). Their ages ranged from 17 to 35 years $(M=19.19, S D=$ $3)$, with more than three-fourth in the 17-19 age group. In terms of educational level, more high school (55\%) than post-high school (45\%) students were enrolled in either computer technology or practical engineering as training specialization. Participants reported that majority of their fathers were employed (58\%), while half of their mothers were unemployed (52\%).

To gather the needed data, the following measures were used.

Beck Depression Inventory-II (BDI-II; Beck et al., 1996) was utilized to evaluate depression-related attitudes and symptoms, with a higher score indicating severe depressive symptoms. The construct and content validity of the BDI-II has been supported in studies of Garcia-Bautista et al. (2018) involving general and hospital populations. In this study, the reliability of BDI-II scores was at $\alpha=.86$.

Beck Anxiety Inventory (BAl; Beck et al., 1988) was utilized to evaluate anxiety symptoms, with a higher score indicating a higher level of anxiety symptoms. Evidence of convergent validity of the BAI has been reported in previous study by Toledano-Toledano et al. (2020). In this study, reliability of BAI scores was at $\alpha=.92$.

Meaning in Life Questionnaire (MLQ; Steger et al., 2006) was utilized to evaluate the presence and search for meaning in life. A higher score indicated a greater degree of presence and searched for meaning. The validity of the MLQ has been demonstrated in cross-sectional studies with samples from the United States (Steger et al., 2006) and China (Huo et al., 2020). In this study, the reliability of MLQ scores was estimated at $\alpha=.86$ for MLQ-meaning and $\alpha=.78$ for MLQ-search.

Satisfaction with Life Scale (SWLS; Diener et al., 1985) was utilized to evaluate the quality of life experienced by students, with the higher score indicating greater life satisfaction. International studies from Greece (Galanakis et al., 2017) and Mexico (Lopez-Ortega et al., 2016) have demonstrated the validity of SWLS. In this study, the reliability of SWLS scores was at $\alpha=.71$.

Positive and Negative Affect Schedule (PNAS; Watson et al., 1988) was utilized to evaluate emotions or mood, with a higher score indicating a higher level of positive or negative emotion. The previous study from Chile (Villarroel et al., 2019) has demonstrated the validity of PNAS. In 
this study, the reliability of PNAS scores was estimated at $\alpha=.87$ for positive affect and $\alpha=.84$ for negative affect.

Academic performance was measured in terms of students' grade point average (GPA) and perceived academic difficulties. Each student's GPA corresponded to the overall average of all subject grades obtained during the semester when the survey was conducted. GPAs ranged from 75 (pass) to 100 (excellent). Academic difficulties were assessed using the Academic Problems Scale (SAPS; Renshaw, 2018), with a higher score indicating the severity of academic problems. Data from adolescents in the United States were utilized to establish preliminary validity evidence. The reliability of SAP scores was estimated at $\alpha=.79$ in this study.

Data gathering was initiated by requesting approval from the school administrator of the research site. Parental informed consent and student assent were obtained before students completed the survey questionnaire during their homeroom period. The survey questionnaire consisted of demographic questions and multiple self-report measures described above. Students' general weighted average (GPA) were provided by the school registrar upon the consent of students. Ethical review and approval for the study was sought from the first author's university. Statistical analyses of data comprised of descriptive statistics and inferential statistics such as chi-square $\left(\chi^{2}\right)$ test, t-test for independent groups, and one-way analysis of variance (ANOVA) for between groups. The effect size was calculated using partial eta squared $\left(\eta^{2}\right)$ and Cohen's $d$.

\subsection{Results}

\section{Descriptive statistics of the study variables}

Table 1 summarizes the descriptive statistics of the study variables, including mean and standard deviations. Skewness and kurtosis values indicated that scores had an approximately normal distribution $(</ 2 /)$ across all variables.

Table 1. Descriptive statistics of study variables

\begin{tabular}{lcccccc}
\hline Variable & Min & Max & M & SD & Skewness & Kurtosis \\
\hline Emotional Distress & & & & & & \\
Depression & 0 & 57 & 17.14 & 10.02 & 0.6 & 0.53 \\
Anxiety & 0 & 53 & 19.90 & 12.39 & 0.38 & -0.66 \\
Negative affect & 10 & 50 & 26.68 & 7.79 & 0.13 & -0.22 \\
Emotional Well-being & & & & & & \\
Positive affect & 10 & 50 & 32.54 & 7.96 & -0.19 & -0.26 \\
Presence of meaning & 5 & 35 & 23.11 & 6.33 & -0.25 & -0.31 \\
Search for meaning & 7 & 38 & 25.85 & 6.51 & -0.43 & -0.23 \\
Quality of life & 5 & 35 & 21.28 & 6.03 & -0.33 & 0.11 \\
Academic performance & & & & & & \\
Academic problems & 1 & 28 & 14.58 & 3.7 & 0.41 & 1.21 \\
GPA & 75 & 98 & 87.1 & 4.51 & -0.57 & 0.2 \\
\hline
\end{tabular}

\section{Emotional functioning profile of participants}

Table 2 reports the emotional functioning profile of the participants. It indicates significant variation in proportion in the distribution of participants. For emotional distress, a more significant proportion of participants was observed to have low to moderate levels than those in the at-risk or clinical level of distress $\left[\chi^{2}(1)=18.63, p=.000\right]$. Concerning well-being, more participants were observed to have moderate to flourishing levels than those in the languishing to low levels $\left[\chi^{2}(1)\right.$ $=17.47, p=.000]$. In terms of bidimensional mental health, approximately half of them reported healthy emotionality, and lower but comparable proportions reported unhealthy, diminished, and mixed emotionality $\left[\chi^{2}(3)=57.29, p=.000\right]$. Based on these results, hypothesis \#1 that posited a larger proportion of students reporting healthy emotionality was confirmed. 
Table 2. Profile of emotional functioning

\begin{tabular}{|c|c|c|}
\hline & \multicolumn{2}{|c|}{ Bidimensional mental health status groups } \\
\hline \multirow{2}{*}{$\begin{array}{l}\text { Emotional } \\
\text { distress }\end{array}$} & \multicolumn{2}{|c|}{ Emotional well-being } \\
\hline & Languishing to low & Moderate to flourishing \\
\hline $\begin{array}{l}\text { Low to } \\
\text { moderate }\end{array}$ & $\begin{array}{l}\text { Diminished emotionality } \\
(n=36,16.90 \%)\end{array}$ & $\begin{array}{l}\text { Healthy emotionality } \\
(n=101,47.42 \%)\end{array}$ \\
\hline $\begin{array}{l}\text { At-risk to } \\
\text { clinical }\end{array}$ & $\begin{array}{l}\text { Unhealthy emotionality } \\
(n=40,18.78 \%)\end{array}$ & $\begin{array}{l}\text { Mixed emotionality } \\
(n=36,16.90 \%)\end{array}$ \\
\hline
\end{tabular}

\section{Group Differences in Emotional Functioning}

Table 3 summarizes the emotional functioning of participants by gender and educational level. Findings indicated significant gender differences in emotional functioning. As to distress, more males were observed to have low to moderate levels while more females were observed to have at-risk or clinical level $\left[\chi^{2}(1)=9.93, p=.002\right.$, Cramer's $\left.V=.23\right]$. In terms of well-being, more males were observed to have moderate to flourishing levels compared to females with approximately equal proportions of languishing to low as well as moderate to flourishing levels $\left[\chi^{2}(1)=4.90, p=.027\right.$, Cramer's $\left.V=.15\right]$. In bidimensional mental health, more males were observed to have healthy emotionality, and more females had unhealthy emotionality. Similar proportions of males and females were observed in the diminished, and mixed emotionality $\left[\chi^{2}(3)=14.75, p=.002\right.$, Cramer's $\left.V=.26\right]$. This suggests that more males may experience positive affect and meaning in life, while more females may experience negative affect and internalizing problems.

Educational level differences in emotional functioning were apparent. More high school students were observed to have languishing to low levels, while more post-high school students were observed to have moderate to flourishing levels of well-being $\left[\chi^{2}(1)=5.57, p=.018\right.$, Cramer's $V=.16]$. In bidimensional mental health, post-high school students were observed to have healthy emotionality, while more high school students had diminished emotionality. Similar proportions of high school and post-high school students were observed to have unhealthy and mixed emotionality $\left[\chi^{2}(3)=7.84, p=.050\right.$, Cramer's $\left.V=.19\right]$. This suggests that both groups of students may have experienced positive feelings and higher quality of life despite feelings of distress and struggling to manage stress even in normal circumstances.

Overall, hypothesis \#2 that posited significant gender and educational level differences in the emotional functioning of students was confirmed.

Table 3. Group differences in emotional functioning

\begin{tabular}{lccccccccc}
\hline & \multicolumn{4}{c}{ Gender } & \multicolumn{3}{c}{ Educational level } \\
\cline { 2 - 10 } Emotional Functioning & \multicolumn{3}{c}{ Male } & \multicolumn{1}{c}{ Female } & High School & Post-HS \\
\cline { 2 - 10 } & $\mathrm{n}$ & $\%$ & $\mathrm{n}$ & $\%$ & $n$ & $\%$ & $n$ & $\%$ \\
\hline Emotional distress & 116 & 70.73 & 22 & 44.90 & 76 & 63.33 & 62 & 66.67 \\
$\quad$ Low to moderate & 48 & 29.27 & 27 & 55.10 & 44 & 36.67 & 31 & 33.33 \\
$\quad$ At-risk to clinical & & & & & & & & \\
\hline Emotional well-being & 52 & 31.71 & 24 & 49.00 & 51 & 42.50 & 25 & 26.88 \\
$\quad$ Languishing to low & 112 & 68.29 & 25 & 51.00 & 69 & 57.50 & 68 & 73.12 \\
$\quad$ Moderate to flourishing & & & & & & & & \\
\hline Bidimensional mental health & & & & & & & & & \\
$\quad$ Diminished emotionality & 30 & 18.29 & 6 & 12.24 & 27 & 22.50 & 9 & 9.68 \\
$\quad$ Healthy emotionality & 85 & 51.83 & 16 & 32.65 & 49 & 40.83 & 52 & 55.92 \\
$\quad$ Unhealthy emotionality & 22 & 13.41 & 18 & 36.73 & 24 & 20.00 & 16 & 17.20 \\
$\quad$ Mixed emotionality & 27 & 16.46 & 9 & 18.37 & 20 & 16.67 & 16 & 17.20 \\
\hline
\end{tabular}




\section{Influence of emotional functioning on life satisfaction and academic functioning}

Table 4 presents the ANOVA results on the influence of emotional functioning on quality of life and academic performance. Findings indicated that distress, well-being, and bidimensional mental health significantly influenced the quality of life of students. As indicated by partial $\eta^{2}$, both well-being and bidimensional mental health have large effect sizes on quality of life and only a moderate effect size for distress. As to academic performance, distress and bidimensional mental health significantly influenced students' academic problems, with a small effect size. On the other hand, well-being did not influence academic problems. Additionally, distress, well-being, and bidimensional mental health did not influence students' GPA. Overall, hypothesis \#3 that posited the significant influence of emotional functioning on the quality of life was confirmed, but partially confirmed for academic performance.

Table 4. Influence of emotional functioning on quality of life and academic problems

\begin{tabular}{llccc}
\hline $\begin{array}{l}\text { Independent } \\
\text { variable }\end{array}$ & Dependent variable & $\mathrm{F}$ & $\mathrm{p}$ & Partial $\eta^{2}$ \\
\hline \multirow{4}{*}{ Emotional distress } & Quality of life & 26.29 & .000 & .11 \\
& Academic problems & 7.53 & .007 & .04 \\
& GPA & .02 & .884 & - \\
\hline \multirow{3}{*}{ Emotional well- } & Quality of life & 59.01 & .000 & .22 \\
being & Academic problems & 1.17 & .281 & - \\
& GPA & 1.92 & .168 & - \\
\hline \multirow{2}{*}{ Bidimensional } & Quality of life & 26.06 & .000 & .27 \\
mental health & Academic problems & 2.70 & .047 & .04 \\
& GPA & .86 & .462 & - \\
\hline
\end{tabular}

Table 5. Planned comparisons of the bidimensional mental health groups on quality of life and academic problems

\begin{tabular}{|c|c|c|c|c|c|c|}
\hline \multirow{2}{*}{ Dependent variables } & \multicolumn{2}{|c|}{ Group } & \multirow{2}{*}{$\begin{array}{c}M \\
\text { Diff } \\
(\mathrm{A}-\mathrm{B})\end{array}$} & \multirow{2}{*}{$t$} & \multirow{2}{*}{$p$} & \multirow{2}{*}{ Cohen's d } \\
\hline & $\mathrm{A}$ & $B$ & & & & \\
\hline \multirow{6}{*}{ Quality of life } & $\mathrm{HE}$ & UE & 8.32 & 8.19 & .000 & 1.53 \\
\hline & $\mathrm{HE}$ & $\mathrm{DE}$ & 4.05 & 4.15 & .000 & .79 \\
\hline & $\mathrm{HE}$ & ME & 1.79 & 1.71 & .090 & - \\
\hline & UE & $\mathrm{DE}$ & -4.17 & -3.79 & .000 & -.87 \\
\hline & UE & ME & -6.53 & -5.66 & .000 & -1.30 \\
\hline & ME & $\mathrm{DE}$ & 2.36 & 2.16 & .034 & .51 \\
\hline \multirow{6}{*}{ Academic problems } & HE & UE & -1.54 & -2.28 & .024 & -.43 \\
\hline & $\mathrm{HE}$ & $\mathrm{DE}$ & -0.42 & -.60 & .548 & - \\
\hline & $\mathrm{HE}$ & ME & -1.62 & -2.29 & .024 & -.45 \\
\hline & UE & $\mathrm{DE}$ & 1.11 & 1.31 & .195 & - \\
\hline & UE & ME & -0.08 & -.09 & .926 & - \\
\hline & $\mathrm{ME}$ & $\mathrm{DE}$ & 1.19 & 1.35 & .182 & - \\
\hline
\end{tabular}

Note: HE- healthy emotionality ( $n=101)$, UE- unhealthy emotionality $(n=40), \mathrm{DE}$ - diminished emotionality ( $n=36)$, ME- mixed emotionality $(n=36)$, M Diff.- observed mean score difference 


\section{Planned comparisons of the bidimensional mental health groups on dependent variables}

To follow up significant ANOVA results, planned comparisons were conducted to compare the bidimensional mental health groups on quality of life and academic problems. As shown in Table 5, students reporting healthy emotionality have a higher quality of life than their peers reporting diminished or unhealthy emotionality. On the other hand, students with unhealthy emotionality reported a much lower quality of life than their peers with diminished or mixed emotionality. As to academic problems, students with healthy emotionality reported lesser academic problems than their peers with unhealthy or mixed emotionality.

\subsection{Discussion}

Findings on the emotional functioning profile of students indicated that approximately half of the students were classified as having healthy emotionality, with smaller but comparable proportions classified as having diminished, mixed, and unhealthy emotionality. This finding is consistent with the study by Renshaw and Cohen (2014), in which most of the participants reported good emotionality and varied proportions in the other three mental health groups. Baumeister and colleagues (2003) described students with healthy emotionality as possessing a higher level of self-esteem that allows them to set higher goals and persevere in the face of adversity. Moreover, Suldo and Shaffer (2008) emphasized that these students may experience healthy relationships and flourish in times of adversity. In contrast, students with diminished and mixed emotionality may demonstrate that happiness is more than just the absence of psychopathology. Although students with low emotionality may not show any signs of distress, they may also feel unhappy and dissatisfied with their lives. Similarly, students with mixed emotionality may experience positive emotions and perceive satisfaction in life despite experiencing emotional distress. Students with unhealthy emotionality may experience inappropriate feelings or behaviors even in normal circumstances, feel unhappy and dissatisfied with life, and struggle in managing stressors, leading to unhealthy relationships, school problems, and difficulty facing life's challenges (Suldo et al., 2016).

The current study found gender differences in students' emotional functioning, with more females reporting at-risk to a clinical level of distress and more males reporting moderate to a flourishing level of well-being, suggesting healthy emotionality. Antaramiran (2015) found similar findings showing that emotional functioning group types were associated with gender differences. Simon and Nath (2004) introduced the sociological theories of emotion to support their findings that men felt positive emotions more frequently than women, and women felt negative emotions more frequently than men. Experience of frequent negative emotions among females can be attributed to biological or hormonal changes that predispose them to intense emotions during stressful situations (Chentsova-Dutton \& Tsai, 2007). Gender roles and expectations are also discovered to increase the likelihood of poor mental health among women. According to the World Health Organization (WHO, 2002), females are pressured to fulfill domestic responsibilities aside from school-related academic and physical stressors. Coping with emotional problems may also differ by gender. Tamres and colleagues (2002) found that females prefer emotion-focused strategies while males prefer active and problem-focused coping strategies when confronted with problems, which in turn may contribute to emotional adjustments and quality of life.

Differences in emotional functioning by educational level were likewise evident in the current study, with more post-high school students reporting healthy emotionality and more high school students reporting diminished and unhealthy emotionality. These differences indicate that compared to high school students, post-high school students tend to be more adjusted and capable of coping with their emotional concerns. Similarly, Halpern-Manners and colleagues (2016) found that a higher educational level is associated with mental health. It enhances interpersonal skills and coping resources that allow individuals to deal with psychological distress. The finding was also reiterated by Sablaon and Madrigal (2021), stating that as students' progress to a higher educational level, experiences in academic training and formation can influence their capacity to manage and overcome adversities. On the other hand, high school students are still in the adolescence developmental stage wherein various physical and psychological changes can occur, including searching for identity, exploring new roles, and transitioning to secondary school. This stage is considered a sensitive developmental period (McGill et al., 2012) that may somehow intensify symptoms of distress (Goldbeck et al., 2007).

Finally, the current study found that students' emotional functioning significantly influenced their quality of life. Specifically, students with healthy emotionality have a higher quality of life 
than their peers with unhealthy or mixed emotionality. Similar results were reported by Suldo and colleagues (2016), suggesting that healthy emotionality may act as a protective factor that improves life quality. Additionally, the current study found that students' emotional functioning significantly influenced their academic problems. In particular, students with unhealthy and mixed emotionality were reported to experience more academic concerns in terms of homework completion, following teacher instructions, or task organization (Renshaw, 2018). In contrast to previous findings, the current study indicated that emotional functioning did not influence GPA. Closer inspection of students' grades suggested skewed distribution with a tendency for higher grades regardless of emotionality classification. This may have been a tangible outcome of the optimal academic support provided to the students in the technical-vocational school covered in the current study. For example, students who have experienced academic challenges are provided with scaffolding through its bridging program to help them achieve the expected competency. Remedial classes and validation exams are given to help them meet learning objectives. Only after all supports are provided that students are evaluated for final grading.

\subsection{Conclusion}

The study extended the application BMHM model in understanding the emotional functioning of technical-vocational students, with most of the students reporting healthy emotionality. Within the model, students' emotional functioning was differentiated by gender and educational level. The findings also suggested that psychological well-being and healthy emotionality are protective factors of quality of life, while distress is considered a risk factor. Moreover, students with healthy emotionality tend to have better school adjustment due to lesser academic problems. Implications of the study reinforced the recommendation of Kim and colleagues (2014) that school-based mental health screening and services should be based on a balanced approach that considers both strength and distress to foster positive development for appropriate mental health programs.

Though the study may seem promising for Filipino students, the following limitations should be considered. First, conclusions cannot be generalized to other students because the data were collected from a sample coming from a single technical-vocational school. Future research may consider a larger number of students from various schools. Second, the study relied on self-report measures that considered internalizing problems as indicators of emotional distress and positive affect, subjective life satisfaction, and meaning in life as indicators of emotional well-being. Future research can include peer or adult reports and observations of emotional functioning. In addition, a broader spectrum of indicators of distress and well-being can be considered.

\section{REFERENCES}

Antaramian, S. (2015). Assessing psychological symptoms and well-being: Application of a dual-factor mental health model to understand college students' performance. Journal of Psychoeducational Assessment, 33 (5), 419-429. https://doi.org/10.1177/0734282914557727

Asenahabi, B. M. (2019). Basics of research design: A guide to selecting appropriate research design. International Journal of Contemporary Applied Researches, 6 (5).

Auerbach, R. P., Alonso, J., Axinn, W. G., Cuijpers, P., Ebert, D.D. Green, J.G., Hwang, I., Kessler, R. C., ... \& Bruffaerts, R. (2016). Mental disorders among college students in the world health organization world mental health surveys. Psychological Medicine, 46 (14), 2955-2970. https://doi.org/10.1017/S0033291716001665.

Baumeister, R. F., Campbell, J. D., Krueger, J. I., \& Vohs, K. D. (2003). Does high self-esteem cause better performance, interpersonal success, happiness, or healthier lifestyles? Psychological Science in the Public Interest, 4(1), 1-44. https://doi.org/10.1111/1529-1006.01431

Beck, A. T., Epstein, N., Brown, G., \& Steer, R. A. (1988). An inventory for measuring clinical anxiety: Psychometric properties. Journal of Consulting and Clinical Psychology, 56, 893-897. https://doi.org/10.1037/0022006X.56.6.893.

Beck, A. T., Steer, R. A., \& Brown, G. K. (1996). BDI-Il manual. San Antonio, TX: Psychological Corporation.

Chentsova-Dutton, Y. E., \& Tsai, J. L. (2007). Gender differences in emotional response among European Americans and among Americans. Cognition and Emotion, 21, 162-181. https://doi.org/10.1080/02699930600911333

Department of Health (DOH). (2020). Your mind matters: DOH calls for a unified response to mental health. https:// doh.gov.ph/press-release/your-mind-matters-doh-calls-for-unified-response-to-mental-health

Diener, E., Emmons, R. A., Larsen, R. J., \& Griffin, S. (1985). The satisfaction with life scale. Journal of Personality Assessment, 49, 71-75. https://doi.org/10.1207/s15327752jpa4901_13 
Dowdy, E., Ritchey, K., \& Kamphaus, R. W. (2010). School-based screening: A population-based approach to inform and monitor childrenss mental health needs. School Mental Health, 2, 166-176. https://doi. org/10.1007/s12310-010-9036-3.

Eklund, K., Dowdy, E., Jones, C., \& Furlong, M. (2010). Applicability of the dual-factor model of mental health for college students. Journal of College Student Psychotherapy, 25, 79-92. https://doi.org/10.1080/87568225.2011.532677

Galanakis, M., Lakioti, A., Pezirkianidis, C., Karakasidou, E., \& Stalikas, A. (2017). Reliability and validity of the satisfaction with life scale (SWLS) in the Greek sample. The International Journal of Humanities and Social Studies, 5 (2). 120-127.

Garcia-Bautista, Z. E., Guerra-Pena, K., Cano-Vindel, A., Herrera-Martinez, S., \& Medrano, L. A. (2018). Validity and reliability of the Beck Depression Inventory (BDI-II) in general and hospital population of Dominican Republic. PLOS ONE, 13 (6). https://doi.org/10.1371/journal.pone.0199750.

Goldbeck, L., Schmitz, T. G., Besier, T., Herschbach, P., \& Henrich, G. (2007). Life satisfaction decreases during adolescence. Quality of Life Research, 16, 969-979. https://doi.org/10.1007/s11136-007-9205-5

Greenspoon, P. J., \& Saklofske, D. H. (2001). Toward an integration of subjective well-being and psychopathology. Social Indicators Research, 54(1), 81-108. https://doi.org/10.1023/A:1007219227883

Grych, J., Taylor, E., Banyard, V., \& Hamby, S. (2020). Applying the dual-factor model of mental health to understanding protective factors in adolescence. American Journal of Orthopsychiatry, 90(4), 458. http:// dx.doi.org/10.1037/ort0000449

Halpern-Manners, A., Schnabel, L., Hernandez, E. M., Silberg, J. L., \& Eaves, L.J. (2016). The relationship between education and mental health: new evidence from a discordant twin study. Social Forces, 95 (1), 107-131. https://doi.org/10.1093/sf/sow035.

Huo, J.Y., Wang, X.Q., Steger, M.F., Ge, Y., Wang, Y. C., \& Liu, M.F. (2020). Implicit meaning of life: The assessment and construct validity of implicit meaning in life and relations with explicit meaning in life and depression. The Journal of Positive Psychology, 15 (4). https://doi.org/10.1080/17439760.2019.1639793.

Keyes, C. L. M. (2002). The mental health continuum: From languishing to flourishing in life. Journal of Health and Behavior Research, 43, 207-222. https://doi.org/10.2307/3090197

Kim, E. K., Furlong, M. J., Dowdy, E., \& Felix, E. D. (2014). Exploring the relative contributions of the strength and distress components of dual-factor complete mental health screening. Canadian Journal of School Psychology, 29 (2), 127-140. https://doi.org/10.1177/0829573514529567.

Lally, J., Samaniego, R. M., \& Tully, J. (2019). Mental health legislation in the Philippines: Philippine mental health act. British Journal of Psychiatry International, 16(3), 65-67. https://doi.org/10.1192/bji.2018.33

LeBuffe, P. A., \& Shapiro, V. B. (2004). Lending "strength" to the assessment of preschool social-emotional health. The California School Psychologist, 9, 51-61. https://doi.org/10.1007/BF03340907

Lopez-Ortega, M., Torres-Castro, S. \& Rosas-Carrasco, O. (2016). Psychometric properties of Satisfaction with Life Scale (SWLS): Secondary analysis of the Mexican Health and aging study. Health and Quality of Life Outcomes, 14, 170. https://doi.org/10.1186/s12955-016-0573-9

McGill, R.K., Hughes, D., Alicea, S., \& Way, N. (2012). Academic adjustment across the middle school: The role of public regard and parenting. Developmental Psychology, 48 (4), 1003-1008. https://doi.org/10.1037/a0026006

Renshaw, T. L. (2018). Preliminary validation of the subjective academic problems scale: A new tool to aid in triaging school mental health screening results. Canadian Journal of School Psychology, 33 (3), 242-256. https://doi.org/10.1177/0829573517702020

Renshaw, T. L. (2017). Technical adequacy of the Positive Experiences at School Scale with adolescents. Journal of Psychoeducational Assessment. Advance online publication. https://doi.org/10.1177/0734282915627920.

Renshaw, T. L., \& Cook, C. R. (2018). Initial development and validation of the Youth internalizing Problems Screener. Journal of Psychoeducational Assessment, 36, 366-378. https://doi.org/10.1177/0734282916679757.

Renshaw, T. L., \& Arslan, G. (2019). Testing the psychological well-being and distress screener with Turkish adolescents. International Journal of School \& Educational Psychology, 7(3), 165-173. https://doi.org/10.1080 /21683603.2017.1414007

Renshaw, T. L., Eklund, K. R., Bolognino, S.J., \& Adodo, I. (2016). Bidimensional emotional health in college students: a comparison of categorical and continuous analytic approaches. Journal of Psychopathology and Behavioral Assessment, 38, 681-694. https://doi.org/10.1007/s10862-016-9558-6.

Renshaw, T. L., \& Cohen, A. S. (2014). Life satisfaction as a distinguishing indicator of college student functioning: Further validation of the two-continua model of mental health. Social Indicators Research, 117, 319-334. https://doi.org/10.1007/s11205-013-0342-7

Rose, T., Lindsey, M. A., Xiao, Y., Finigan-Carr, N.M., \& Joe, S. (2017). Mental health and educational experiences among black youth: A latent class analysis. Journal of Youth Adolescence, 46: 2321-2340. https://doi. org/10.1007/s10964-017-0723-3

Sablaon, C. M., \& Madrigal, D. V. (2021). Adolescent psychological well-being: The case of Filipino Catholic high school students with absentee parents. Philippine Social Science Journal, 4(1), 31-41. https://doi. org/10.52006/main.v4i1.322

Seligman, M. (2018): PERMA and the building blocks of well-being. The Journal of Positive Psychology. https://doi. org/10.1080/17439760.2018.1437466

Seligman, M. E. P., \& Csikszentmihalyi, M. (2000). Positive Psychology. American Psychologist, 55(1), 5-14. https:// 
doi.org/10.1037/0003-066X. 55.1. 5

Simon, R. W., \& Nath, L. E. (2004). Gender and emotion in the United States: Do men and women differ in selfreports of feelings and expressive behavior? American Journal of Sociology, 109(5), 1137-1176.

Singh, K., \& Jha, S. D. (2008). Positive and negative affect and grit as predictors of happiness and life satisfaction. Journal of the Indian Academy of Applied Psychology, 34(2), 40-45.

Slade, M. (2010). Mental illness and well-being: The central importance of positive psychology and recovery approaches. BMC Health Services Research 201010:26. https://doi.org/10.1186/1472-6963-10-26

Steger, M. F., Frazier, P., Oishi, S., \& Kaler, M. (2006). The meaning in life questionnaire: Assessing the presence of and search for meaning. Journal of Counseling Psychology, 53 (1), 80-93. https://doi.org/10.1037/00220167.53.1.80.

Subramani, C., \& Kadhiravan, S. (2017). Academic stress and mental health among high school students. Indian Journal of Applied Research, 7 (5).

Suldo, S. M., Thalii-Raitano, A., Kiefer, S., \& Ferron, J. (2016). Conceptualizing high school students' mental through a Dual-Factor Model. School Psychology Review, 45 (4), 434-457.

Suldo, S. M., \& Shaffer, E. J. (2008). Looking beyond psychopathology: The Dual-Factor Model of mental health in youth. School Psychology Review, 37 (1), 52-68. https://doi.org/10.1080/02796015.2008.12087908

Tamres, L. K., Janicki, D., \& Helgeson, V. S. (2002). Sex differences in coping behavior: A meta-analytic review and an examination of relative coping. Personality and Social Psychology Review, 6, 2-30. https://doi.org/10.1207/ S15327957PSPR0601_1

Toledano-Toledano, I., De la Rubia, J. M., Dominguez-Guedea, M. T., Nabors, L. A., Barcelata-Eguiarte, B. E., RochaPérez, E., Luna, David., Leyva-López, A., \& Rivera-Rivera, L. (2020). Validity and reliability of the Beck Anxiety Inventory (BAI) for family caregivers of children with cancer. International Journal of Environmental Research and Public Health, 17 (21), 7765. https://doi.org/10.3390/ijerph17217765.

Villaroel, P., Urzua, A., Jaime, D., Contreras, D., Zych, I., Celis-Atenas, K., Silve, J. R., \& Lillo, S. (2019). Positive and negative affect schedule (PNAS): Psychometric properties and discriminative capacity in several Chilean samples. Evaluation and the Health Professionals, 42 (4), 473-497. https://doi. org/10.1177/0163278717745344

World Health Organization (2002). Gender and mental health. http://apps.who.int/iris/bitstream/ handle/10665/68884/a85573.pdf;jsessionid=09576FA1449A9BF7AE7F841AED3274AA?sequence $=1$

Watson, D., Clark, L. A., \& Tellegen, A. (1988). Development and validation of brief measures of positive and negative affect: the PANAS scales. Journal of personality and social psychology, 54(6), 1063-70.

World Health Organization (2020). World mental health day: An opportunity to kick-start a massive scale-up in investment in mental health. https://www.who.int/news/item/27-08-2020-world-mental-health-day-anopportunity-to-kick-start-a-massive-scale-up-in-investment-in-mental-health.

World Health Organization (2018) mental health atlas 2017. https://www.who.int/publications/i/ item/9789241514019

World Health Organization (WHO) (2015). Global school-based student health survey results: 2015.https://apps. who.int/iris/bitstream/handle/10665/272526/9789290225911-eng.pdf?sequence=1\&isAllowed=y.

\section{Correspondence:}

MYREEN P. CLEOFE*

University of Santo Tomas- Manila, Philippines

https://orcid.org/0000-0002-6806-7629

CARMELO M. CALLUENG

carmelo.callueng@gmail.com

https://orcid.org/0000-0002-4907-0806

LUCILA O. BANCE

lobance2@gmail.com

https://orcid.org/0000-0002-0626-8839

\section{*Corresponding Author}

